\title{
Papillary thyroid microcarcinoma: active surveillance in the follow-up of persistence structural disease
}

\author{
P Bellitti, A Carbone, D Cito and R Bruno* \\ Department Medicine, Unit of Endocrinology, Tinchi Hospital, ASM Matera, Italy
}

\section{Letter to the editor}

Dear Editor-in-Chief,

We report the case of a 20 -years-old patient underwent thyroid surgery because of a papillary thyroid microcarcinoma's (PTC) diagnosis at fine needle biopsy (FNAB). Patient' history revealed a familiarity for PTC (mother) and a previous diagnosis of pre-pre B cells lymphoblastic leukemia at 15 years, treated with chemotherapy and radiotherapy, followed by bone marrow transplantation. Pathology confirmed the diagnosis of PTC $(9 \mathrm{~mm})$ with infiltration of soft tissues. After the haematological consult, he underwent to thyroid ablation with $2220 \mathrm{MBq}$ of ${ }^{131} \mathrm{I}$ with after recombinant TSH (rhTSH) [1]. Whole body scan (WBS) after ${ }^{131} \mathrm{I}$ did not shown any area of abnormal radioiodine up-take (RAIU). US neck scan performed six months after RAIU revealed a hypo-echoic nodular tissue in left thyroid bed $(4 \times 3 \times 7$ $\mathrm{mm}$ ); serum thyroglobulin ( $\mathrm{Tg}$ ) was $0.31 \mathrm{ng} / \mathrm{ml}$ and anti-thyroglobulin autoantibodies (TgAb) were absent. FNAB of this lesion was positive for local persistent malignancy. US imaging performed 12 months after radioiodine, confirmed the presence of the same micronodule $(4 \times 5 \times 5 \mathrm{~mm})$ in the left thyroid bed. Tg dosage after rh TSH was $0.8 \mathrm{ng} / \mathrm{mL}, \mathrm{TgAb}$ were absent with TSH $73.76 \mathrm{mcUI} / \mathrm{ml}$. Patient was submitted to a strictly follow-up with US and $\mathrm{Tg} / \mathrm{Tg} \mathrm{Ab}$ dosage every six months. Four years after therapy, US scanning did not show any increase of the micro nodule and any sospicious latero cervical lymphnode; $\mathrm{Tg}$ was $0.2 \mathrm{ng} / \mathrm{mL}$, TgAb were alway absent with TSH $0.2 \mathrm{mcUI} /$ mL. 2015 ATA guide lines for the diagnosis and treatment of thyroid differentiated carcinoma state that active surveillance management approach can be considered as an alternative to immediate surgery, in patient with biopsy proven low-risk thyroid carcinoma. These indications take into account the observation that surgery, as the first choice, may cause morbidity due to adverse events [2,3]. In our case, the presence of a focus of papillary thyroid microcarcinoma in the left thyroid bed after surgery and RAIU indicated a persistent structural incomplete disease [2]. In this condition, considering the risk for the patient to undergone to a second RAIU, due to bone marrow radio exposure, and the mortality for a local persistence (11\%), a strictly follow-up was indicated. We can conclude that the active surveillance should be considered in follow-up of persistent structural incomplete disease, if additional treatments are at high risk of unfavorable events. These observations enforce the concept that the management of PTC should also be tailored on the base of patients features.

\section{Conflict of interest}

The Authors declare that they have no conflict of interest or founding.

\section{Ethical approval}

The therapeutic and diagnostic procedures were in accordance with ethical standards of the institutional and/or national research committee and with the 1964 Helsinki declaration and its later amendments or comparable ethical standard.

\section{References}

1. Castagna MG, Cantara S, Pacini F (2016) Reappraisal of the indication for radioiodine thyroid ablation in differentiated thyroid cancer patients. J Endocrinol Invest 39: 10871094.

2. Haugen BR, Alexander EK, Bible K, Doherty G, Mandel Sj, et al. (2016) 2015 American thyroid association management guidelines for adult patients with thyroid nodules and differentiated thyroid cancer. Thyroid 26: 1-133.

3. Oda H, Miyanuchi A, Ito Y (2016) Incidence of unfavourable events in the management of low-risk papillary microcarcinoma of the thyroid by active surveillance versus immediate surgery. Thyroid 26: 150-155.
Copyright: (C2018 Bellitti P. This is an open-access article distributed under the terms of the Creative Commons Attribution License, which permits unrestricted use, distribution, and reproduction in any medium, provided the original author and source are credited.
Correspondence to: Rocco Bruno, Department Medicine, Unit of Endocrinology, Tinchi Hospital, ASM Matera, Italy, Tel: +39- 0835586561; E-mail: roccobruno1@ virgilio.it

Key words: papillary, microcarcinoma, active surveillance

Received: March 08, 2018; Accepted: March 21, 2018; Published: March 26 2018 